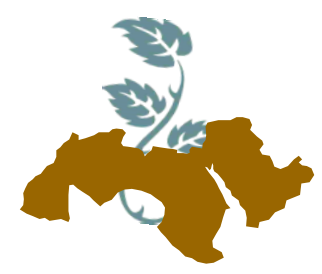

\author{
1225 \\ Arab Univ. \\ J. Agric. Sci., \\ Ain Shams Univ., Cairo \\ Special Issue, 26(2A), 1225-1237, 2018
}

\title{
GENOTYPIC VARIATIONS IN SALT TOLERANCE OF SOME EGYPTIAN WILD BEET ACCESSIONS
}

\author{
Hussin S.A. \\ Agric. Botany Dept., Fac. of Agric., Ain Shams Univ., Cairo, Egypt
}

Keywords: Seawater salinity, wild beet, ion leakage, $\mathrm{Na}^{+} / \mathrm{K}^{+}$ratio, carbohydrate concentratios

\section{ABSTRACT}

This study reports for the first time the ecophysiological responses of some Egyptian wild beet accessions (WB1013, WB1021 and WB1026) under saline irrigation. The plants were exposed to five seawater salinities $(0,20,30,40$ and $60 \%$ sws) for 6 weeks in a sandy culture in the greenhouse. Low salinity ( $20 \%$ sws) slightly enhanced the plant fresh weight of both WB1013 and WB1021 genotypes by $5 \%$ and $3 \%$ respectively, but significantly reduced that of WB1026 genotype by about $10 \%$. Higher seawater salinities, however, caused progressive growth reductions in all accessions, with maximum growth inhibition, being $59 \%$ in WB1026 at $60 \%$ sws. Tolerance threshold was lowest (being at $20 \%$ sws) for WB1026, but highest (reached $40 \%$ sws) for both genotypes WB1013 and WB1021. EC 50 was at salinity level of $40-60 \%$ sws for WB1026 genotype, but higher than $60 \%$ sws for genotypes WB1013 and $W B 1021$. These indicate that both accessions WB1013 and WB1021 are more salt-tolerant when compared with $W B 1026$. The higher salt tolerance of WB1013 and WB1021 accessions is largely conferred by higher leaf $\mathrm{K}^{+} / \mathrm{Na}^{+}$ratio, due to low $\mathrm{Na}^{+}$and $\mathrm{Cl}^{-}$accumulation under saline conditions compared to WB1026. This was associated with lower dry weights and ion leakage, and with higher leaf area, chlorophyll readings, total soluble carbohydrates and $\mathrm{Ca}^{2+}$ concentrations when compared with WB1026. Both WB1013 and WB1021 accessions do not only offer the possibility of being an alternative promising cash crops under seawater irrigation, but also, through an understanding of its physiology, may provide possible routes to enhance salt tolerance in other beet crops.

\section{INTRODUCTION}

Soil salinity is gaining great attention world over, due to its negative impacts on plant growth, crop yield and thus food security, particularly under arid climates (Hussin et al 2017). Due to some estimates, $8 \%$ of the earth's surface and more than $30 \%$ of the global irrigated lands are salt-affected (Hajiboland 2013). The widespread of soil salinization is becoming even more prevalent on the eve of the global climate changes (Lavania et al 2015). At present about $1 \times 10^{6}$ ha cultivated area in Egypt is salt-affected, due to improper irrigation and drainage practices (Barbouchi et al 2015). Efforts to develop high yielding crops for saltaffected environments using conventional breeding and gene manipulation have been intensified over the past 25 years (Flowers, 2004). The outcomes, although promising, remain not significant so far, due to the multi-genic nature of the trait and comparatively limited gene pool available (Koyro et al 2013). The development of halophytes, which constitute about $1 \%$ of the world's flora (Flowers \& Colmer 2008) to useful plants "cash crops" would be a feasible and efficient solution that fosters crop productivity on salt-hit areas (Rozema \& Flowers 2008). Owing to their high salt tolerance and diverse options of use, particularly for economic interests (food, fodder) or ecological reasons (soil desalinisation, dune fixation, $\mathrm{CO}_{2}$-sequestration), cash crop halophytes has entered the realm of economic feasibility in the world's developed and developing countries (Lieth \& Mochtschenko 2002). Wild beet, Beta vulgaris ssp. maritima (L.), the halophyte ancestor of the existing beets ( $B$. vulgaris) (Biancardi et al 2012), can be an excellent cash crop with enormous potentials for marginal and salt-affected areas (Koyro et al 2006). The first use of $B$. maritima goes back to prehistory, when the leaves and roots were harvested and 
domesticated as raw vegetable or potherb (von Boguslawski 1984). The leaves and roots have been also used against several ailments and diseases (Biancardi et al 2012). Its center of origin is widely thought to be the Middle East, from where it spread west into the Mediterranean and north along the Atlantic seacoast and into the mountains of Turkey (Biancardi et al 2012). Thought wild beet is closely related to the other cultivated forms of beet (i.e., table, leaf, fodder and sugar beet) (Pink 1993), it is distinguished with specific allele composition, exhibiting potentially higher salt tolerance (Daoud et al 2008 and Rozema et al 2015). A precondition for judicious utilisation of a promising candidate halophyte such as wild (sea) beet is precise and detailed information about its level of salinity tolerance and the various mechanisms enabling the plant to grow at (their natural) saline habitats (Koyro et al 2006). Reportedly, salinity tolerance is a multifarious feature, governed by an array of interconnected physiological, morphological and biochemical mechanisms operating at cellular, organ and whole plant level (Munns \& Tester 2008 and Flowers et al 2015). Although the degree and the specific mechanism(s) of tolerance may vary from species to the other, all these mechanisms are largely connected to the major constraints of plant growth under saline conditions: (i) water deficit, (ii) restriction of $\mathrm{CO}_{2}$ uptake, (iii) ion toxicity, and (iv) ion imbalance (Eisa et al 2012 and Hussin et al 2017). A number of investigations have indicated that wild beet plants were able to adjust osmotically to maintain a positive water balance in response to water salinity (Koyro \& Huchzermeyer 1999 and Daoud et al 2008). Osmotic adjustment in sea beet was mainly achieved by massive accumulation of inorganic ions $\left(\mathrm{Na}^{+}\right.$ and $\mathrm{Cl}^{-}$) in plant tissues, particularly in the leaves (Koyro et al 2006 and Dauod et al 2008). In most cases, osmotic adjustment by salt inclusion was associated with a reduction in $\mathrm{K}^{+}, \mathrm{Ca}^{2+}$ and $\mathrm{Mg}^{2+}$ contents, leading to extreme ion ratios within the plant tissues (Koyro et al 2006 and Daoud et al 2008). In the tap root of salt-stressed wild beet, ion $\left(\mathrm{Na}^{+}, \mathrm{K}^{+}, \mathrm{Ca}^{2+}\right.$ and $\mathrm{Mg}^{2+}$ ) concentrations were found to be low to explain the low osmotic potential values (Daoud et al 2008). The concentrations of organic osmolytes, mainly soluble carbohydrates and proline, were high enough to compensate the osmotic stress imposed by saline treatments (Koyro et al 2006 and Daoud et al 2008). A considerable amount of evidence has accumulated recently, proving the existence of genetic diversity within $B$. maritima, which has evolved due to inter- actions of genetic, climatic, and soil factors (Andrello et al 2015). This genetic variance is considered essential for survival at hostile environments (de Vilmorin 1923), and might represent a valuable genetic resource within the goal of broadening sugar beet gene pool for biotic and abiotic stresses (Panella \& Lewellen 2007). Despite an apparent interest in using wild beet as a model system, a potential donor of salt tolerance genes, and even as a potential halophytic cash crop, very little is known about the differences in salt tolerance level and the mechanisms conferring this tolerance in the Egyptian wild beet accessions. Against this background, this study aims mainly at monitoring salt-induced responses of three Egyptian wild beet accessions to get precise insights into the salt tolerance threshold and individual adaptive mechanisms conferring tolerance differences (if any) in these closely related beet accessions. This may open prospects to select the most promising genotype(s) for more comprehensive field trials and point out physiological targets for breeding program aimed at improving salt tolerance of other beet crops.

\section{MATERIALS AND METHODS}

\section{Plant materials, experimental design and growth conditions}

This study was performed at the greenhouse of Agricultural Botany Dept., Fac. of Agric., Ain Shams Univ., Egypt. Two successive agricultural seasons were performed during 2014-2015 and 2015-2016 to investigate the eco-physiological responses of some Egyptian wild beet accessions to seawater irrigation. Three wild beet accessions (Beta vulgaris subsp. maritima) from different geographical and ecological zones were selected from twenty-six genotypes of Egyptian core collection. Table (1) shows the location, international database Beta number (IDBBNR) and international accession number (ID) for the selected accessions. The seeds of these accessions were kindly provided by Dr. Alan L. Hodgdon, USDA, ARS, USA. They were washed with distilled water to remove any germination inhibitor and sown (on December 25, 2014 for the first season and on December 31, 2015 for the second season) in black plastic pots (25 cm diameter), filled with washed quartz sand (12.5 kg each, dry weight base). The pots were kept on a bench in the greenhouse at ambient temperature of $20 \pm 3^{\circ} \mathrm{C}$ (daytime) and $13 \pm 3^{\circ} \mathrm{C}$ (night time), a photoperiod of $9-10 \mathrm{~h}$, relative 
humidity $45-70 \%$ and light intensity of $1500-$ $2000 \mu \mathrm{mol} \mathrm{m} \mathrm{m}^{-2} \mathrm{~s}^{-1}$. The pots were watered manually with tap water every 2-day intervals for 2 weeks. After the emergence of the true leaves (three weeks after germination), the seedlings were thinned to three seedlings of uniform size per pot. The plants were irrigated with Hoagland nutrient solution, modified by Johnson (Johnson et al 1957) and the soil water holding capacity was maintained at $50-60 \%$. Salinity treatments started after 2 weeks by adding seawater to the nutrient solution step-wisely until the final concentrations were achieved to avoid salt shock injuries. Chemical analyses and mineral contents of the seawater used for irrigation in this study are presented in Table (2). There were altogether five salinity treatments (five replicate pots each treatment): 1.4 , $10,15,20$, and $30 \mathrm{dS} \mathrm{m}^{-1}$ (equivalent to 0, 20, 30, 40 and $60 \%$ seawater salinity). Salinity treatments were performed for a total period of six weeks.

\section{Harvest procedure and growth parameters measurement}

Plants of each accession were destructively harvested (three replicates from each treatment). The plants were separated into roots and leaves. The root segments were gently cleaned from sand and washed with distilled water to remove excess of nutrients and salts. They were then blotted carefully with tissue paper to remove the surface water. The fresh weights of both roots (RFW) and leaves (LFW) were directly recorded. Salinity tolerance threshold (seawater salinity that caused an initial significant reduction in the maximum fresh weight; Shannon \& Grieve 1999) and $\mathrm{EC}_{50}$ (seawater level that reduces maximum plant fresh by $50 \%$ ) were determined. The area of the uppermost three fully expanded mature leaves was recorded using LI-3100C area meter (LI-COR, Inc., Lincoln, NE, USA). For the determination of water contents, plant materials were dried in an oven at $70^{\circ} \mathrm{C}$ until constant weight was obtained.

\section{Determination of electrolyte (ion) leakage}

Electrolyte leakage was determined according to Lutts et al (1996), with minor modification by cutting $1 \mathrm{~cm}$ diameter leaf disks from young leaves of each accession. Leaf discs were washed with distilled water to remove adhered electrolytes and then blotted carefully with tissue paper to remove the surface water. One gram of these washed leaf disks was immersed in $10 \mathrm{ml}$ distilled water in stopped sigma tube, placed on orbital shaker with gently agitation (100 rpm) for $2 \mathrm{~h}$ at room temperature. Electrical conductivity of the agitated solution $\left(E C_{\text {initial }}\right)$ was measured, before the samples were autoclaving. The electrical conductance of the solution was measured again after autoclaving $\left(\mathrm{EC}_{\mathrm{fi}-}\right.$ nal). Percentage of electrolyte (ion) leakage was then calculated using the following formula:

$$
\text { Electrolyte leakage }(\%)=\left(E C_{\text {initial }} / E C_{\text {final }}\right) X 100
$$

\section{Determination of chlorophyll}

Chlorophyll content of the young, but fully expanded leaves which grew completely under the treatment was determined with a chlorophyll meter SPAD-502Plus (Konica Minolta, Marunouchi, Japan).

\section{Determination of root total soluble carbohy- drates}

Chopped dried roots were grinded in a stainless steel Wiley mill to a fine powder and used to determine root total soluble carbohydrate spectrophotometerically according to Dubois et al (1956).

\section{Determination of inorganic ion concentrations}

Approximately $0.2 \mathrm{~g}$ of pulverized dried leaves were weighed and digested as described by Wolf (1982). The cleared cool extracts were filtered and completed to a final volume of $50 \mathrm{ml}$ with distilled water. $\mathrm{Na}^{+}$and $\mathrm{K}^{+}$concentrations in these extracts were measured using a Flame emission photometer (JENWAY, PFP-7, ELE Instrument Co. Ltd., UK). $\mathrm{Ca}^{2+}$ concentration was measured using an atomic absorption spectrophotometer (Perkin Elmer model PE 2100). Chloride $\left(\mathrm{Cl}^{-}\right)$was determined in the dried tissue by titration against $0.05 \mathrm{~N}$ silver nitrate using potassium chromate as an indicator as described by Diatloff and Rengel (2001).

\section{Statistical analysis}

All data sets were subjected to a two-wayANOVA analysis using the SPSS for Windows statistical data analysis package (SPSS Inc., 2002, release 16 , Chicago, IL, USA) in order to determine if significant differences were existed between seawater salinity and accessions. Tukey's HSD multiple comparison post-hoc tests were employed to determine if significant $(P \leq 0.05)$ differences occurred between individual treatments and accessions. 
Table 1. Some information about the screened wild beet accessions. WB No, local wild beet number; IDBB NR, international database Beta number; Accession ID, international wild beet accession number

\begin{tabular}{|c|c|c|c|c|c|}
\hline WB No & Location & Latitude & Longitude & IDBB NR & Accession ID \\
\hline WB-1013 & Alexandria & $31.0 \mathrm{~N}$ & $30.2 \mathrm{E}$ & 9742 & PI 562591 \\
WB-1021 & Fayyum & $29.2 \mathrm{~N}$ & $30.9 \mathrm{E}$ & 9794 & PI 562599 \\
WB-1026 & Luxor & $25.0 \mathrm{~N}$ & $32.5 \mathrm{E}$ & 9753 & PI 562604 \\
\hline
\end{tabular}

Table 2. Chemical analysis of seawater used for salinity treatments and tap water used for diluting seawater

\begin{tabular}{|c|c|c|c|c|c|c|c|c|c|c|}
\hline \multirow{3}{*}{$\begin{array}{l}\text { Water } \\
\text { source }\end{array}$} & \multirow{3}{*}{ pH } & \multirow{3}{*}{$\begin{array}{c}E C \\
\left(d S ~^{-1}\right)\end{array}$} & \multicolumn{8}{|c|}{$\mathrm{meq} / \mathrm{L}$} \\
\hline & & & \multicolumn{4}{|c|}{ Cations } & \multicolumn{4}{|c|}{ Anions } \\
\hline & & & $\mathrm{Ca}^{++}$ & $\mathrm{Mg}^{++}$ & $\mathrm{Na}^{+}$ & $\mathrm{K}^{+}$ & $\mathrm{SO}_{4}^{--}$ & $\mathrm{CO}_{3}{ }^{--}$ & $\mathrm{HCO}_{3}^{-}$ & $\mathrm{Cl}^{-}$ \\
\hline Sea & 7.68 & 62.19 & 93 & 147 & 635 & 15 & 122.5 & 0.21 & 3 & 508 \\
\hline Tap & 6.57 & 0.448 & 3 & 4 & 1.15 & 0.2 & 0.42 & Nil & 1.0 & 2 \\
\hline
\end{tabular}

\section{RESULTS}

\section{Growth parameters}

\section{Fresh weight}

Comparative growth responses of different Egyptian wild beet accessions (WB1013, WB1021 and WB1026) to different seawater salinities (0, $20,30,40$ and $60 \%$ sws) (6 weeks treatment) are illustrated in Figure (1). Under control conditions, the genotype WB1013 exhibited relatively the highest fresh weight (216.6 g/plant), followed by WB1021 (165.5 g/plant) and WB1026 (126.5 g/plant) (Fig. 1). Low seawater salinity (20\% sws) slightly enhanced the plant fresh weight of both WB1013 and WB1021 genotypes by 5\% and 3\% respectively, compared to the relative controls. However, it led to a significant reduction of about $10 \%$ in the fresh weight of WB1026 genotype compared to the controls. Higher seawater salinities, however, caused progressive growth reductions in the three wild beet accessions under evaluation, with maximum growth inhibition, being $59 \%$ in WB1026 at $60 \%$ sws (Fig. 1). The plants displayed conspicuous growth and continued to develop new leaves even at the highest salinity treatment, although with some symptoms of ion deficiency and/or toxicity, particularly in the genotype WB1026. Salinity tolerance threshold was lowest for WB1026 (being at 20\% sws), but highest for both genotypes WB1013 and WB1021 (reached $40 \%$ sws) (Fig. 1). $E_{50}$ was at salinity level of $40-60 \%$ sws for WB1026 genotype, but at salinity level higher than $60 \%$ sws for genotypes WB1013 and WB1021 (Fig. 1).

\section{Dry weight partitioning}

The response of dry weight to seawater salinity differed greatly between under- and aboveground parts and between beet genotypes (Fig. 2a and b). As a general trend, raising water salinity substantially declined the root dry weight of the three accessions under evaluation. Salt-induced reduction in root dry weight was greatest in WB1026 (being $35.2 \%)$, followed by WB1013 (30.5\%) and WB1021 (27.1\%). In tendency, seawater salinity resulted in a significant increase in the leaf dry weight of WB1026, but did not significantly influence that of WB1013 and WB1021 accessions (Fig. 2a and b). The roots and leaves of WB1013 and WB1021 genotypes, however, showed significantly lower dry matter compared to the other genotype at the whole range of salinities $(P \leq 0.05)$. 


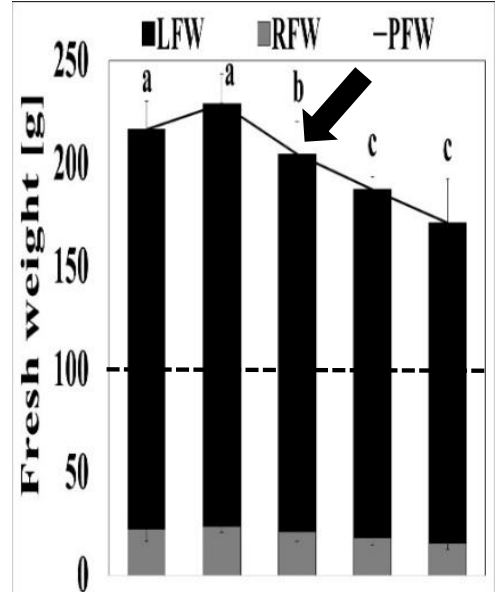

Ctr. $\quad 20 \% \quad 30 \% \quad 40 \% \quad 60 \%$ (A) Seawater salinity

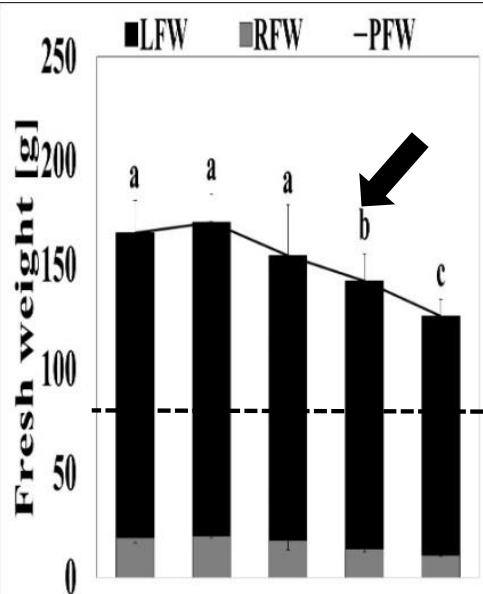

Ctr. $\quad 20 \% \quad 30 \% \quad 40 \% \quad 60 \%$ (B) Seawater salinity

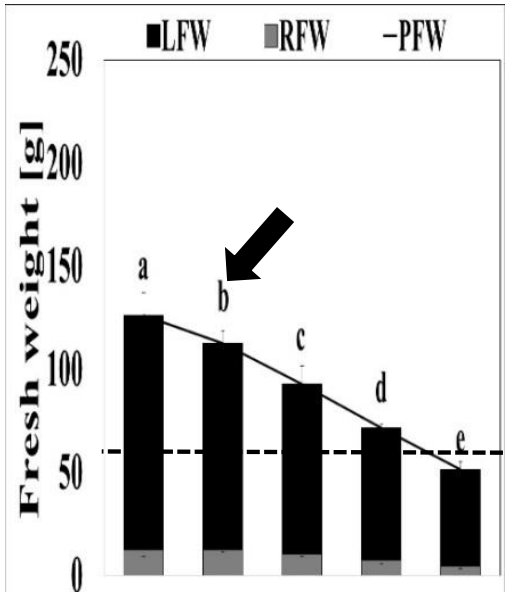

Ctr. $\quad 20 \% \quad 30 \% \quad 40 \% \quad 60 \%$

(C) Seawater salinity

Fig. 1. Development and growth responses of the roots and leaves (expressed as fresh weights) of some Egyptian wild beet accessions upon exposure to elevating seawater salinity. (A) WB1013, (B) WB1021 and (C) WB1026. LFW, leaf fresh weight; RFW, root fresh weight; PFW, plant fresh weight. Arrows mark the salinity resistance threshold, while the dotted lines mark EC50 values. Each column represents the mean values of six replicates $\pm \mathrm{SE}$. Columns with the same letter are not significantly different at $P \leq 0.05$, Tukey's HSD multiple comparison post-hoc tests.
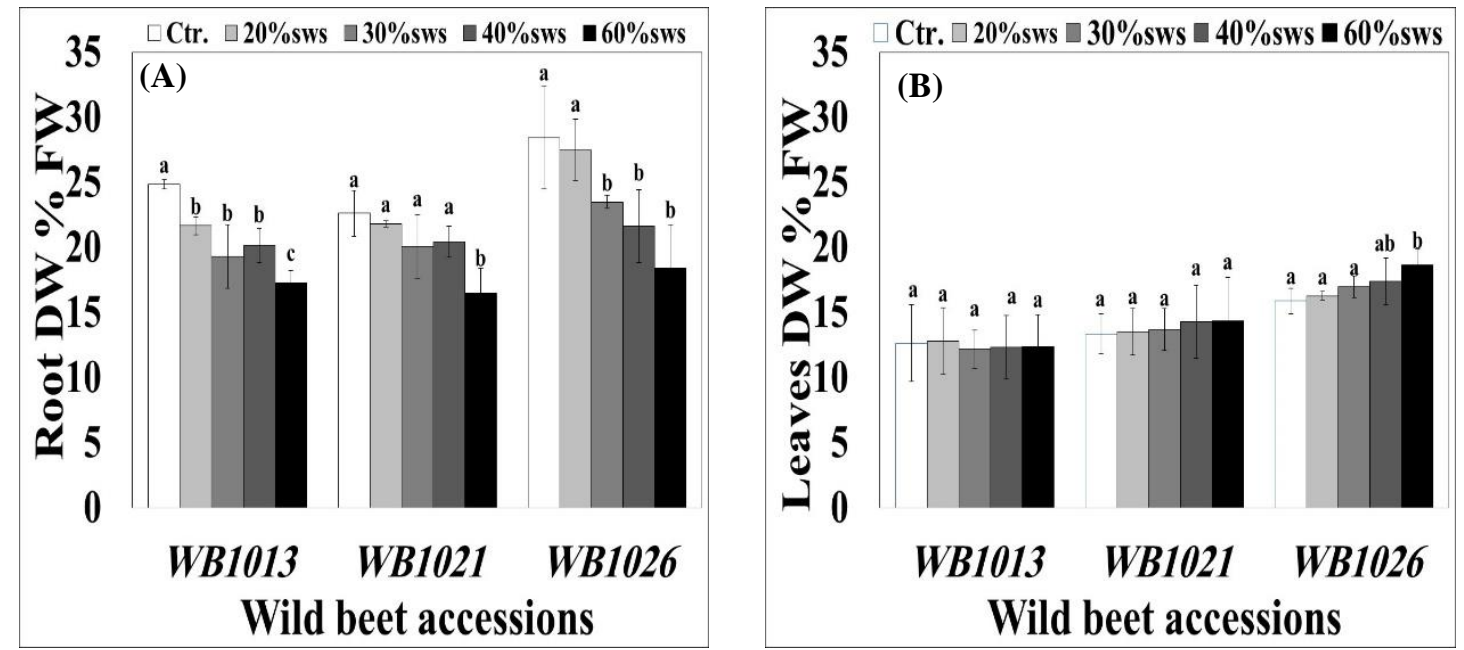

Fig. 2. Effect of seawater salinity level on the dry weight of the root (A) and leaves (B) of some Egyptian wild beet accessions. Each column represents the mean values of six replicates $\pm S E$. Columns with the same letter are not significantly different at $P \leq 0.05$, Tukey's HSD multiple comparison post-hoc tests 


\section{Surface leaf area}

Seawater substantially and significantly $(P \leq$ 0.05 ) reduced the surface leaf area per leaf of all wild beet genotypes tested, with maximum reductions observed at the highest salinity treatment (Fig. 3). Salt-induced reduction in leaf area was greatest in WB1026 (48.8\%), but lowest in WB1013 (18.8\%) genotype (Fig. 3). At all salinity levels, leaf area was highest for accessions WB1013 and WB1021 (Fig. 3).

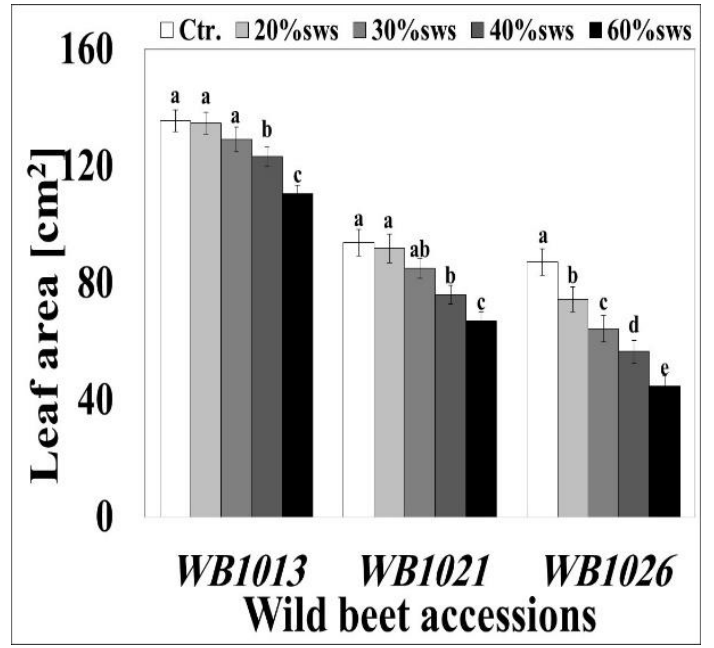

Fig. 3. Effect of seawater salinity level on the surface leaf area of some Egyptian wild beet accessions. Each column represents the mean values of six replicates $\pm \mathrm{SE}$. Columns with the same letter are not significantly different at $P \leq 0.05$, Tukey's HSD multiple comparison post-hoc tests

\section{Electrolyte (ion) leakage}

Raising seawater salinity gradually and significantly $(P \leq 0.05)$ increased electrolyte leakage of all wild beet accessions under the evaluation, with less adverse effect on both WB1013 and WB1021 (Fig. 5). Wild beet accessions WB1013 and WB1021 exhibited the lowest ion leakage (being 76.2 and $77.8 \%$, respectively), while WB1026 genotype had the highest ion leakage (reached $89.1 \%$ ) in response to high seawater salinity (Fig. 5).

\section{Chlorophyll contents}

SPAD readings were highest for WB1013 and WB1021 genotypes under control conditions (Fig. 4). For all wild beet accessions, SPAD values were transiently increased in response to elevating seawater salinity, reached a maximum at seawater salinity of $40 \%$ sws (Fig. 4). Thereafter, it declined significantly, although with less severe effects on the genotypes WB1013 and WB1021 (Fig. 4).

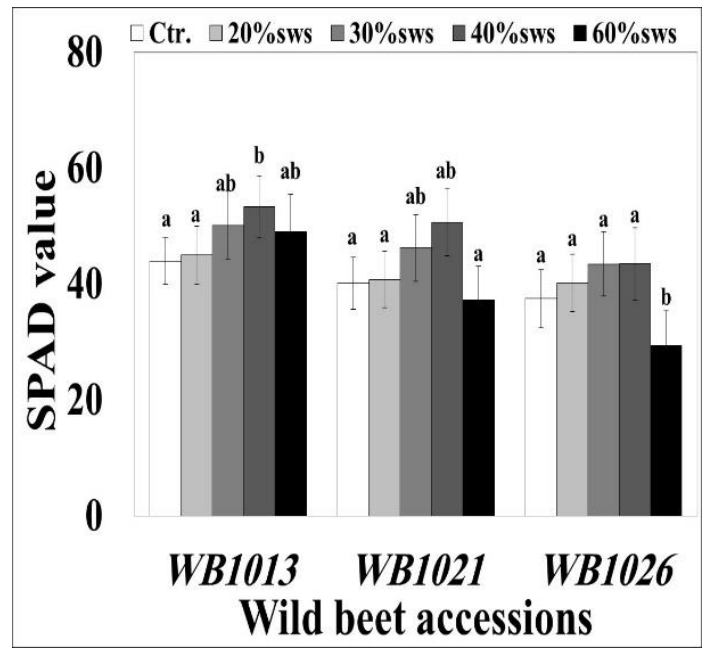

Fig. 4. Effect of seawater salinity level on leaf chlorophyll readings of some Egyptian wild beet accessions. Each column represents the mean values of six replicates $\pm \mathrm{SE}$. Columns with the same letter are not significantly different at $P \leq 0.05$, Tukey's HSD multiple comparison post-hoc tests.

\section{Root total soluble carbohydrates (TSC)}

As a general trend, TSC increased significantly $(P \leq 0.05)$ and gradually in all wild beet accessions under evaluation as seawater salinity rose (Fig. 6). Again, the roots of both wild beet accessions WB1013 and WB1021 exhibited significantly the highest carbohydrate concentration, reached up to $30.5 \%$ and $28.2 \%$, respectively, at the highest salinity treatment (Fig. 6). 


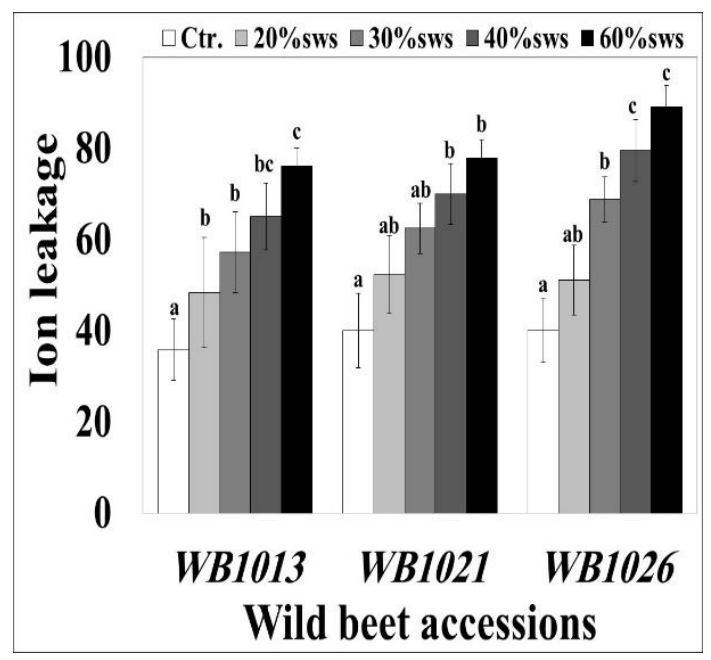

Fig. 5. Ion leakage of different wild beet accession in response to seawater salinity. Each column represents the mean values of six replicates \pm SE. Columns with the same letter are not significantly different at $P \leq 0.05$, Tukey's HSD multiple comparison post-hoc tests.

\section{Leaf ion concentration}

Analysis of variance revealed that leaf $\mathrm{Na}^{+}$ concentrations were increased progressively and significantly $(P \leq 0.05)$ in all wild beet accessions as seawater level increased (Fig. 7a). High salinity level resulted in $9.1-9.4$ fold increases in leaf $\mathrm{Na}^{+}$ concentration relative to the respective controls, depending on the genotype. At this salinity level, the leaves of WB1026 genotype had distinctly the highest $\mathrm{Na}^{+}$concentration (being 13.66\%), followed by WB1013 (12.52\%) and WB1021 (11.99\%) (Fig. 7a). The same pattern was also observed for $\mathrm{Cl}^{-}$, i.e. it increased progressively as seawater salinity raised (Fig. 7b). Salt-mediated increases in leaf $\mathrm{Cl}^{-}$concentration were lowest $(7.2$ and 7.9 folds) for WB1013 and WB1021 genotypes, respectively, but highest $(9.8$ fold $)$ for WB1026 genotype (Fig. 7b). Whatever the salinity

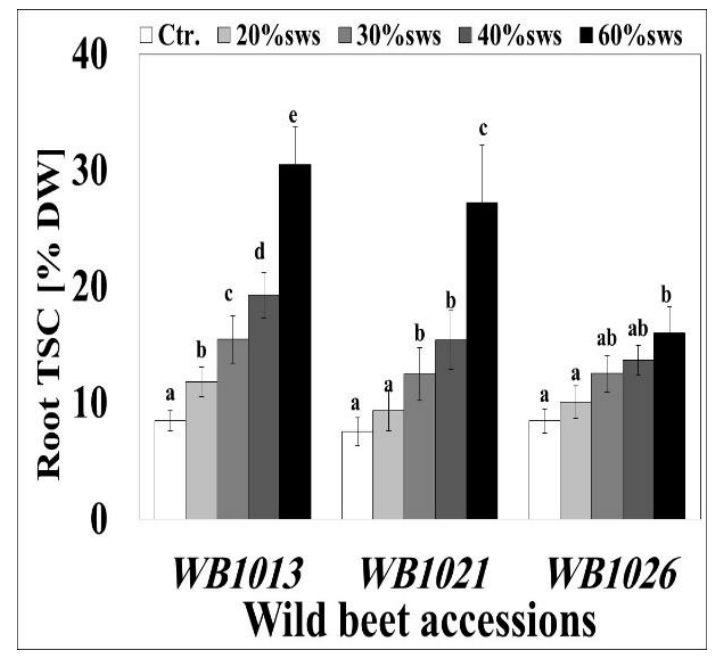

Fig. 6. Effect of seawater salinity level on the root TSC in some wild beet accessions. Each column represents the mean values of six replicates \pm SE. Columns with the same letter are not significantly different at $P \leq 0.05$, Tukey's HSD multiple comparison post-hoc tests.

treatment, plants of accessions WB1013 and WB1021 showed comparatively higher leaf $\mathrm{K}^{+}$ concentrations (Fig. 7c). Leaf $\mathrm{K}^{+}$concentrations decreased steadily and significantly $(P \leq 0.05)$ as seawater salinity increased, reached their minimum at the highest salinity treatment (Fig. 7c). This effect was much more pronounced for the plants of WB1026 genotype, where high water salinity led to reduce leaf $\mathrm{K}^{+}$concentration by more than $85 \%$ compared to the respective controls (Fig. 7c). Leaf $\mathrm{Ca}^{2+}$ concentrations were reduced upon exposure to seawater salinity in all wild beet accessions, with more adverse effect on WB1026 genotype, where leaf $\mathrm{Ca}^{2+}$ reduced by $86 \%$, relative to the controls, at the highest water salinity (Fig. 7d). Salt-induced reductions in leaf $\mathrm{Ca}^{2+}$ were only $63 \%$ and $67 \%$ for WB1013 and WB1021 genotypes, respectively (Fig. 7d). 

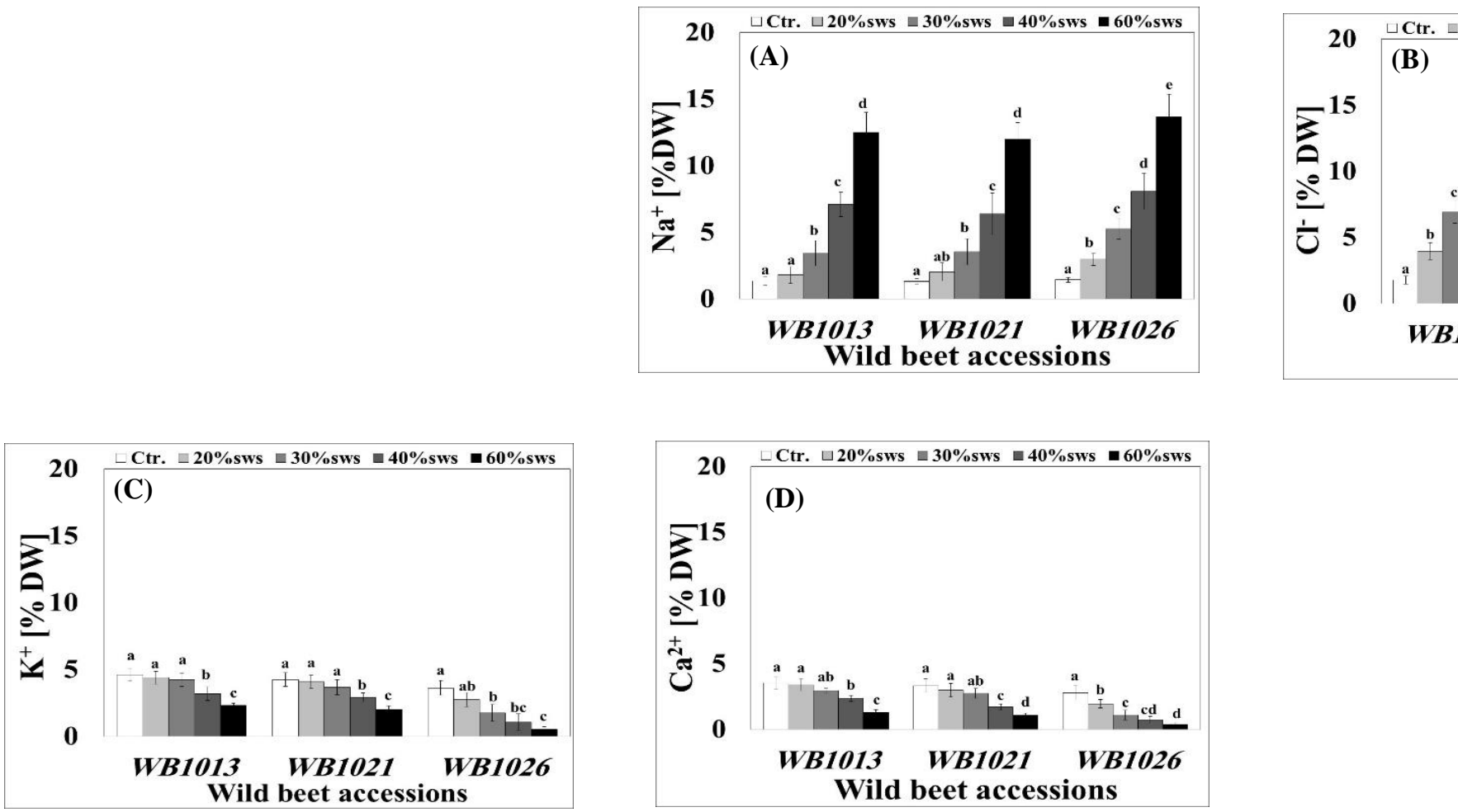

Fig. 7. Effect of seawater salinity levels on leaf $\mathrm{Na}^{+}(\mathrm{A}), \mathrm{Cl}^{-}(\mathrm{B}), \mathrm{K}^{+}(\mathrm{C})$ and $\mathrm{Ca}^{2+}(\mathrm{D})$ contents of different wild beet accessions. Each column represents the mean values of six replicates \pm SE. Columns with the same letter are not significantly different at $P \leq 0.05$, Tukey's HSD multiple comparison post-hoc tests

\section{DISCUSSION}

Phenotypic variations in plant growth and biomass production were evident among sea beet accessions even when grown under non-saline conditions. Wild beet accessions WB1013 and WB1021 had comparatively higher fresh weight and leaf area per plant compared to WB1026 accessions (Fig. 1 and 3). Similarly, significant differences in plant growth have been reported in $B$. vulgaris, and attributed to the wide genetic variability in this species (Ghoulam et al 2002; Wu et al 2013 and Rozema et al 2015). Plant fresh weight was differentially influenced with raising seawater salinity. While low seawater salinity $(20 \%)$ slightly stimulated the growth of both WB1013 and WB1021 genotypes, it significantly declined the fresh weight of WB1026 genotype (Fig. 1). Saltstimulated growth under moderate salinity has been also reported previously in sea beet (Koyro et al 2006; Daoud et al 2008 and Rozema et al 2015) and many other halophytic species (Ramos et al 2004; Eisa et al 2012 and Hussin et al 2013). The mechanisms underlying growth promo- tion of halophytic species at low and moderate salinities remain unclear (Flowers \& Colmer 2008). Salt-induced growth stimulation in WB1013 and WB1021 genotypes might be largely the consequence of increased tissue water content as has been suggested for other halophytic species (Eisa et al 2012 and Hussin et al 2013). High water salinity $(60 \%$ sws), however, drastically reduced the fresh weight of all accessions, and again the screened accessions displayed considerable level of variability for salt tolerance. Plants of both WB1013 and WB1021 genotypes were least affected by high salinity treatments, exhibiting biomass reductions of about $20 \%$ and $21 \%$, respectively, while those of WB1026 were most sensitive, with reduction of about $59 \%$ (Fig. 1). Interestingly, plants of all accessions showed conspicuous growth and developed new leaves even at the highest salinity treatment, albeit with some symptoms of ion deficiency and/or toxicity, particularly those of genotype WB1026. Reduced plant biomass in response to high substrate salinity is quite common in many halophytic species, including sea beet (Koyro et al 2006 and Daoud et al 2008) 
and sugar beet (Ghoulam et al 2002; Eisa et al 2011; Wu et al 2013 and Rozema et al 2015). As can be seen in Figure (1), salt tolerance threshold was the lowest (at 20\% sws) for WB1026 accession, but highest (at 40\% sws) for both WB1013 and WB1021 accessions (Fig. 1). Furthermore, the $E_{50}$ value was lowest (at $40-60 \%$ sws) for WB1026 genotype, but highest (at salinity level higher than 60\% sws) for WB1013 and WB1021 genotypes (Fig. 1). Taken together, the relative declines in biomass accumulation, $\mathrm{EC}_{50}$ and salinity tolerance threshold; these indicate that both accessions WB1013 and WB1021 are more salttolerant, while WB1026 is more salt sensitive. These genotypic variations in biomass accumulation over the course of the experiment suggest that changes in plant fresh weight is a sensitive method for determining wild beet responses to salt stress. Several factors may function as a bottleneck for plant growth at high salinities (Eisa et al 2012 and Hussin et al 2013). The initial detrimental effect of salinity is due to an osmotic constraint that the plant encounters in rooting medium (Hussin et al 2017). Results of previous studies showed that sea beet could efficiently reduce the water potential below that of the substratum as a consequence of decreased tissue osmotic potential to maintain a positive water balance even under high saline conditions (Koyro et al 2006 and Daoud et al 2008). Reportedly, salt-induced reductions in water and osmotic potentials is associated concurrently with a substantial accumulation of osmotically active solutes. Osmotic adjustment by massive accumulation of inorganic ions was amply reported in many dicotyledonous halophytic species (Geissler et al 2009 and Hussin et al 2013). For the three wild beet accessions, elevating seawater salinity resulted in a substantial excessive accumulation of $\mathrm{Na}^{+}$and $\mathrm{Cl}^{-}$and decreased $\mathrm{K}^{+}$and $\mathrm{Ca}^{2+}$ concentrations in the leaves (Fig. 7a, b, c and d). Similar results have been reported in sea beet (Daoud et al 2008 and Koyro et al 2006), sugar beet (Daoud et al 2008; Eisa et al 2011 and Wu et al 2013). This implies that these wild beet accessions may behave - at the whole plant level- as salt includers, utilizing inorganic ions (less energy and carbon demanding compared to the adjustment by organic solutes) to adjust osmotically (Koyro \& Huchzermayer 1999 and Koyro et al 2006). This was further supported by the positive correlation between leaf dry weight and ion $\left(\mathrm{Na}^{+}\right.$and $\left.\mathrm{Cl}^{-}\right)$accumulation in response to increasing seawater salinity. In our study, significant differences in $\mathrm{Na}^{+}$ and $\mathrm{Cl}^{-}$accumulation were observed between the three wild beet accessions. Among the screened accessions, WB1013 and WB1021 had comparatively the lowest accumulation of $\mathrm{Na}^{+}(9.1$ folds for both) and $\mathrm{Cl}^{-}$(7.2 and 7.9 folds respectively). A possible explanation for the variation in ion accumulation could be due to genotypic difference in the rate of ion uptake and xylem loading between these accessions. In line with the results of Shabala et al (2013), this allow to speculate that plants of WB1013 and WB1021 (more salt-tolerant) accessions exert more efficient mechanisms to control ion $\left(\mathrm{Na}^{+}\right.$and $\left.\mathrm{Cl}^{-}\right)$uptake, translocation and sequestration at the whole plant level. High $\mathrm{Na}^{+}$ and $\mathrm{Cl}^{-}$accumulation in excess of what is needed for osmotic adjustment might lead to tissue dehydration and/or ion toxicity. This would result ultimately in growth reduction, inhibition of new leaf initiation and the formation of smaller ones, some with symptoms of nutrient disorders as observed at high salinity in WB1026 accession (least salttolerant). Salt-induced increases in $\mathrm{Na}^{+}$concentrations were associated with drastic decreases in $\mathrm{K}^{+}$ in all the three accessions (Fig. 7c). This is in agreement with the findings from most of the published results (Koyro et al 2006 and Daoud et al 2008). Such a response has been interpreted as a result of competition between $\mathrm{K}^{+}$and $\mathrm{Na}^{+}$uptake at the root level (Hasegawa et al 2000) or due to the changes in the membrane integrity caused by the displacement of $\mathrm{Ca}^{2+}$ by $\mathrm{Na}^{+}$(Marschner 1995 and Tester \& Davenport 2003). According to Blumwald et al (2000), salt tolerance is, partially, related to the plant ability to avoid $\mathrm{Na}^{+}$accumulation and/or to maintain adequate levels of $\mathrm{K}^{+}$in the shoots. Intriguingly, plants of both genotypes WB1013 and WB1021 (most salt-tolerant) exhibited higher leaf $\mathrm{K}^{+}$concentrations (Fig. 7c). Consequently their leaves maintained comparatively higher $\mathrm{K}^{+} / \mathrm{Na}^{+}$ratio $(0.19 \pm 0.08$ and $0.18 \pm 0.07)$, while those of $W B 1026$ exhibited low $\mathrm{K}^{+} / \mathrm{Na}^{+}$ratio $(0.03 \pm 0.02)$ at the highest seawater salinity level. The substantial differences in $\mathrm{Na}^{+}$and $\mathrm{K}^{+}$accumulation between these wild beet accessions may attribute basically to the differences in selective ion uptake and transport capacities at root level as reported by Wang et al (2002). Consistent with previous studies (Blumwald et al 2000 and Munns \& Tester 2008), this confirms that leaf $\mathrm{K}^{+} / \mathrm{Na}^{+}$ratio could be a key physiological trait for salinity tolerance screening in wild beet. As has been previously assumed, $\mathrm{Na}^{+}$can replace $\mathrm{K}^{+}$to a certain degree in some cellular activities, especially in its osmotic functions (Mäser et al 2002). This might explain, at least in part, why the growth of 
both WB1013 and WB1021 genotypes was enhanced at low seawater salinities when $\mathrm{K}^{+}$concentrations reduced. Since $\mathrm{K}^{+}$has been implicated in turgor regulation and enzymes activation, including enzymes involved in chlorophyll biosynthesis and RubisCo (Marschner 1995; Shabala 2003 and Munns \& Tester 2008), severe reduction in $\mathrm{K}^{+}$ concentrations in wild beet may have also contributed to the decreased leaf expansion, leaf area and hence plant fresh weight in seawater-treated plants. Results of the present study showed that the chlorophyll values were significantly reduced in all wild beet accessions upon exposure to high salinity treatment, although with less severe effects on the most salt-tolerant genotypes, i.e. WB1013 and WB1021 (Fig. 4). Salt-mediated reductions in chlorophyll were widely reported under saline conditions (Geissler et al 2009 and Eisa et al 2012). Ion deficiency, disturbance of chloroplast membrane, instability of the pigment protein complex and enhanced chlorophyllase activity might contribute to the reduction in chlorophyll values under saline condition (Marschner 1995). Raising seawater salinity resulted also in a significant reduction in leaf $\mathrm{Ca}^{2+}$ concentrations in all sea beet accessions (Fig. 7d). Similar observations were reported for sea beet (Koyro \& Huchzermeyer 1999; Koyro et al 2006 and Daoud et al 2008), sugar beet (Wu et al 2013) and many other halophyte species (Wyn Jones \& Gorham 2002). As mentioned before, high $\mathrm{Na}^{+}$concentration is thought to displace $\mathrm{Ca}^{2+}$ from the plasma membrane, causing a loss of membrane integrity and hence an increased ion leakage (Tester \& Davenport 2003). This was shown by the trends of electrolyte leakage (Fig. 5), which increased markedly as the seawater salinity rose. Increasing electrolytes leakage due to elevating water salinity has been also reported in wild beet (Bor et al 2003), sugar beet (Ghoulam et al 2002), spinach plants (Kaya et al 2001) and rice (Lutts et al 1996). Yet, the most salt tolerant wild beet accessions WB1013 and WB1021 exhibited clearly the lowest ion leakage, whereas WB1026 genotype (least salt-tolerant) had the highest ion leakage in response to high seawater salinity (Fig. 5), indicating severe disturbance in membrane permeability for the latter under salt stress. This conclusion is further confirmed by the fact that reductions in leaf $\mathrm{K}^{+}$ and $\mathrm{Ca}^{2+}$ were lowest in WB1013 and WB1021 genotypes (most salt-tolerant) compared to WB1026 genotype (least salt-tolerant) at the highest water salinity (Fig. 7d). An important group of compatible solutes that was investigated in these beet accessions is the carbohydrates. Increasing seawater salinity was connected with a noticeable increase in root TSC in all accessions, albeit with significant differences between genotypes (Fig. 6). Carbohydrate accumulation as a response to salinity has been reported previously in sea beet (Koyro et al 2006 and Daoud et al 2008) and sugar beet (Eisa et al 2011) and considered to play an important role in osmotic adjustment (Koyro et al 2006). Several hypotheses have been mentioned to explain carbohydrates accumulation, even with suppressed photosynthesis, under salt stress. TSC accumulation is assumed to result initially from decreased export as a result of shortage of energy source (e.g. ATP) (Munns \& Termaat 1986) or disturbed carbohydrate metabolism, regulated by various synthesizing and degrading enzymes that might be ion-specifically controlled (Marschner 1995). In addition to their role as osmolytes, carbohydrates are presumed to be osmoprotectant involved in stabilizing cellular membranes, protecting proteins and enzymes, acting as a stress signal or as free radical scavengers (Ashraf \& Foolad 2007). These functions coincided with our results associating carbohydrate concentrations and membrane leakage in the most salt tolerant accessions WB1013 and WB1021.

\section{CONCLUSION}

Results of the present study justified the potentials of wild beet as a highly salt tolerant subspecies (in terms of biomass production) able to grow, produce and reproduce at $60 \%$ sws. The ecophysiological responses of the screened wild beet accessions to seawater irrigation allow for the speculation that all of the considered parameters were affected by salinity with a varietal difference. WB1026 was the less tolerant accession, whereas WB1013 and WB1021 were the more tolerant ones. Higher salt tolerance of WB1013 and WB1021 accessions is largely conferred by lower leaf $\mathrm{K}^{+} / \mathrm{Na}^{+}$ratio, as a result of low $\mathrm{Na}^{+}$and $\mathrm{Cl}^{-}$ accumulation under saline conditions compared to WB1026. This was coincided with lower dry weight and ion leakage, but higher leaf area, chlorophyll values, TSC and $\mathrm{Ca}^{2+}$ concentrations when compared with WB1026. Finally yet importantly, both WB1013 and WB1021 accessions do not only offer the possibility of being an alternative promising cash crop under seawater irrigation, but also, through an understanding of its physiology, may provide possible routes to enhance salt tolerance in other beet crops. 


\section{ACKNOWELEDGEMENTS}

The author would like to thank Dr. Alan L. Hodgdon, USDA, ARS, USA, for providing the seeds of the Egyptian wild beet accessions used in this study. The author is also indebted to Dr. E. H. Abd El-Samad, Department of Vegetables Crop Research, National Research Centre, Egypt, for the critical readings and corrections of the draft of the manuscript and his recommendations.

\section{REFERENCES}

Andrello, M., Henry, K., Devaux, P., Desprez, B. and Manel, S. 2015. Taxonomic, spatial and adaptive genetic variation of Betasection Beta. TAG. Theor. Appl. Genet., 129, 257-271.

Ashraf, M. and Foolad, M.A. 2007. Improving plant abiotic-stress resistance by exogenous application of osmoprotectants glycine betaine and proline. Environ. Exp. Bot., 59, 206-216.

Barbouchi, M., Abdelfattah, R., Chokmani, K., Ben Aissa, N., Lhissou, R. and El Harti, A. 2015. Soil salinity characterization using polarimetric InSAR Coherence: Different case studies in Tunisia and Morocco. IEEE Journal, 8, 3823 - 3832.

Biancardi, E., Panella, L.W. and Lewellen, R.T. 2012. Beta maritima, the origin of beets. New York, Springer, pp. 85 - 136.

Blumwald, E., Aharon, G.S. and Apse, M.P. 2000. Sodium transport in plant cells. Biochemica et Biophysica Acta, 1465, 140 - 151.

Bor, M., Özdemir, F. and Türkan, I. 2003. The effect of salt stress on lipid peroxidation and antioxidants in leaves of sugar beet Beta vulgaris L. and wild beet Beta maritima L. Plant Sci., 164, 77 - 84.

Daoud, S., Harrouni, C., Huchzermeyer, B. and Koyro, H.W. 2008. Comparison of salinity tolerance of two related subspecies of Beta vulgaris: the sea beet (Beta vulgaris ssp. maritima) and the sugarbeet (Beta vulgaris ssp. vulgaris). In Abdelly, C., Öztürk, M., Ashraf, M. and Grignon, C., (Eds.), Biosaline agriculture and high salinity tolerance. pp. 115 - 130 . Birkhauser Verlag Basel den virtuellen flora.

De Vilmorin, J.L. 1923. L' hérédité de la betterave cultivée. Gauthier-Villars, Paris, France

Diatloff, E. and Rengel, Z. 2001. Compilation of simple spectrophotometric techniques for the determination of elements in nutrient solutions. J. Plant Nutr., 24, 75 - 86.

Dubois, M., Gilles, K.A., Hamilton, J.K., Robers, P.A. and Smith, F. 1956. Colorimetric method to determination of sugars and related substances. Anal. Chem., 28, 350 - 356.
Eisa, S.S., Hussin, S. and Abd El-Samad, E.H. 2011. Enhancement of sugar beet productivity under saline conditions. J. App. Sci. Res., 7, 2063 - 2072.

Eisa, S., Hussin, S., Geissler, N. and Koyro, H.W. 2012. Effect of $\mathrm{NaCl}$ salinity on water relations, photosynthesis and chemical composition of quinoa (Chenopodium quinoa Willd.) as a potential cash crop halophyte. Aust. J. Crop Sci., 6, $357-368$.

Flowers, T.J. 2004. Improving crop salt tolerance. J. Exp. Bot., 55, 307-319.

Flowers, T.J. and Colmer, T.D. 2008. Salinity tolerance in halophytes. New Phytol., 179, 945-963.

Flowers, T.J., Munns, R. and Colmer, T.D. 2015. Sodium chloride toxicity and the cellular basis of salt tolerance in halophytes. Annals Bot., 115, 419 - 431.

Geissler, N., Hussin, S. and Koyro, H.W. 2009. Interactive effects of $\mathrm{NaCl}$ salinity, elevated atmospheric $\mathrm{CO}_{2}$ concentration on growth, photosynthesis, water relations and chemical composition of the potential cash crop halophyte Aster tripolium L. Environ. Exp. Bot., 65, 220 $-231$.

Ghoulam, C., Foursy, A. and Fares, K. 2002. Effects of salt stress on growth, inorganic ions and proline accumulation in relation to osmotic adjustment in five sugar beet cultivars. Environ. Exp. Bot., 47, 39-50.

Hajiboland, R. 2013. Role of Arbuscular mycorrhiza in amelioration of salinity. In Ahmad, P., Azooz, M. A. and Prasad, M. N. V. (Eds.), Salt stress in plants: Signalling, Omics and Adaptations, pp. 301-354, New York, NY, Springer.

Hasegawa, P.M., Bressan, R.A., Zhu, J.K. and Bohnert, H.J. 2000. Plant cellular and molecular responses to high salinity. Annu. Rev. Plant Physiol. Plant Mol. Biol., 51, 463 - 499.

Hussin, S., Geissler, N. and Koyro, H.W. 2013. Effect of $\mathrm{NaCl}$ salinity on Atriplex nummularia (L.) with special emphasis on carbon and nitrogen metabolism. Acta Physiol. Plant., 35, 1025 - 1038.

Hussin, S., Geissler, N., El-Far, M.M.M. and Koyro, H.W. 2017. Effects of salinity and shortterm elevated atmospheric $\mathrm{CO}_{2}$ on the chemical equilibrium between $\mathrm{CO}_{2}$ fixation and photosynthetic electron transport of Stevia rebaudiana Bertoni. Plant Physiol. Biochem., 118, 178 - 186.

Johnson, C.M., Stout, R.R., Broyer, T.C. and Carlton, A.B. 1957. Comparative chlorine requirements of different plant species. Plant and Soil, 8, 337 - 353. 
Kaya, C., Higgs, D. and Kirnak, H. 2001. The effects of high salinity $(\mathrm{NaCl})$ and supplementary phosphorus and potassium on physiology and nutrition development of spinach. Bulg. J. Plant Physiol., 27, 47 - 59.

Koyro, H.W. and Huchzermeyer, B. 1999. Influence of high $\mathrm{NaCl}$-salinity on growth, water and osmotic relations of the halophyte Beta vulgaris ssp. maritima - Development of a quick check. In Hamdy, A, Lieth, H., Todorovic, M. and Moschenko, M. (Eds.), Halophytes uses in different climates I, pp. 89 - 103.

Koyro, H.W., Daoud, S., Harrouni, C. and Huchzermeyer, B. 2006. Strategies of a potential cash crop halophyte ( Beta vulgaris ssp. maritima ) to avoid salt injury. Trop. Ecol., 47, $191-200$.

Koyro, H.W., Hussain, T., Huchzermeyer, B. and Khan, M.A. 2013. Photosynthetic and growth responses of a perennial halophytic grass Panicum turgidum to increasing $\mathrm{NaCl}$ concentrations. Environ. Exp. Bot., 91, 22 - 29.

Lavania, D., Dhingra, A., Siddiqui, M.H., AlWhaibi, M.H. and Grover, A. 2015. Current status of the production of high temperature tolerant transgenic crops for cultivation in warmer climates. Plant Physiol. Biochem., 86, $100-108$.

Lieth, H. and Mochtschenko, M. 2002. Halophyte uses in different climates IV. Cash crop halophytes for future halophytes growers. Leiden, Backhuys Publishers, NL, pp. $15-35$.

Lutts, S., Kinet, J.M. and Bouharmont, J. 1996. $\mathrm{NaCl}$ induced senescence in leaves of rice (Oryza sativa L.) cultivars differing in salinity resistance. Annals Bot., 78, 389 - 398.

Marschner, H. 1995. Mineral Nutrition of Higher Plants. $2^{\text {nd }}($ Ed.), pp. 243-267, Academic Press, London, UK.

Mäser, P., Gierth, M. and Schroeder, J. 2002. Molecular mechanism of potassium uptake in plants. Plant and Soil, 247, 43 - 54.

Munns, R., Termaat, A., 1986. Whole plant responses to salinity. Aust. J. Plant Physiol., 13, $143-160$.

Munns, R. and Tester, M. 2008. Mechanisms of salinity tolerance. Annu. Rev. Plant Biol., 59, $651-681$.

Panella, L. and Lewellen, R.T. 2007. Broadening the genetic base of sugar beet: introgression from wild relatives. Euphytica, 154, 382 400.

Pink, D.A. 1993. Beet root, Beta vulgaris subsp. vulgaris. In Kallo, G. and Berg, B.O., (Eds.), Genetic Improvement of Vegetable Crops, pp. 473 - 477, Pergamon Press, Oxford, UK.
Ramos, J., Lopez, M. J. and Benlloch, M. 2004. Effect of $\mathrm{NaCl}$ and $\mathrm{KCl}$ salts on the growth and solute accumulation of the halophyte Atriplex nummularia. Plant and Soil, 259, 163 - 168.

Rozema, J. and Flowers, T. 2008. Crops for a salinized world. Science, 322, 1478 - 1480.

Rozema, J., Cornelisse, D., Zhang, Y., Li, H., Bruning, B., Katschnig, D., Broekman, R., Ji, B. and van Bodegom, P. 2015. Comparing salt tolerance of beet cultivars and their halophytic ancestor: consequences of domestication and breeding programmes. AOB Plants 7, plu083, doi:10.1093/aobpla/plu083

Shabala, S. 2003. Regulation of potassium transport in leaves: From molecular to tissue level. Annals of Botany, 92, 627 - 634 .

Shabala, S., Hariadi, Y. and Jacobsen, S.E. 2013. Genotypic difference in salinity tolerance in quinoa is determined by differential control of xylem $\mathrm{Na}^{+}$loading and stomatal density. J. Plant Physiol., 17, 906 -914.

Shannon, M.C. and Grieve, C.M. 1999. Tolerance of vegetable crops to salinity. Scientia Horticulturae, 78, $5-38$.

Tester, M. and Davenport, R. 2003. $\mathrm{Na}^{+}$tolerance and $\mathrm{Na}^{+}$transport in higher plants. Annals Bot., 91, 503 - 527.

von Boguslawski, E. 1984. Zur Geschichte der Beta-Rübe als Kulturpfl anze bis zum Beginn des 19. Jahrhundert. Institut für Zuckerrübenforschung, Göttingen, Berlin, Germany

Wang, S., Zheng, W., Ren, J. and Zhang, C. 2002. Selectivity of various types of saltresistant plants for $\mathrm{K}^{+}$over $\mathrm{Na}^{+}$. J. Arid Environ., 52, $457-472$.

Wolf, B. 1982. A comprehensive system of leaf analysis and its use for diagnosing crop nutrients status. Commun. Soil Sci. Plant Anal., 13, 1035 - 1059.

Wu, G.Q., Liang, N., Feng, R.J. and Zhan, J.J., 2013. Evaluation of salinity tolerance in seedlings of sugarbeet (Beta vulgaris L.) cultivars using proline, soluble sugars and cation accumulation criteria. Acta Physiol. Plant., 35, 2665 - 2674.

Wyn Jones, R.G. and Gorham, J. 2002. Intraand intercellular compartmentation of ions - a study in specificity and plasticity. In Läuchli, A. and Lüttge, U., (Eds.), Salinty: environmentplants-molecules. Dordrecht: pp. 159-180. Kluwer Academic Publishers. 